\title{
Complicações relativas às infecções odontogênicas: Angina de Ludwig
}

\author{
Complications concerning odontogenic infections: Ludwig Angina
}

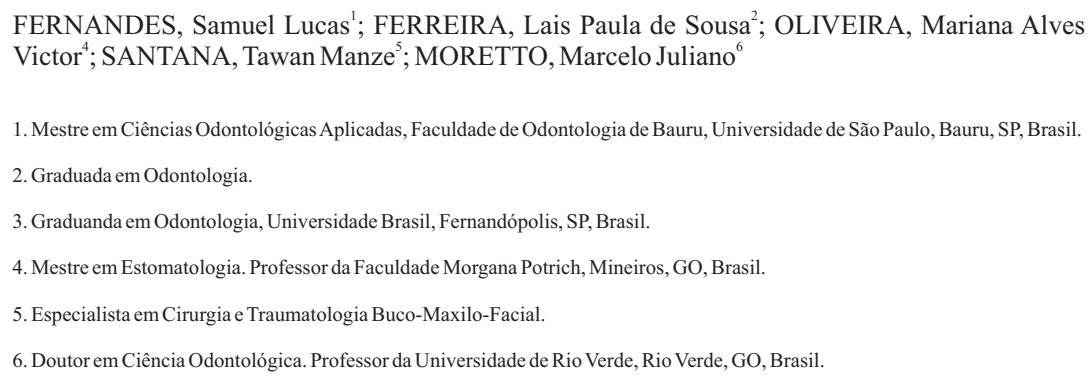

Endereço para correspondência:

Samuel Lucas Fernandes

Faculdade de Odontologia de Bauru - USP

Disciplina de Endodontia

Alameda Doutor Octávio Pinheiro Brisolla, 9-75

17012-901 - Bauru - São Paulo - Brasil

E-mail: samuel.lukas.usp@gmail.com

Recebido: 08.05.2017

Aceito: 30.06 .2017

\section{RESUMO}

Descrita em 1836 como sendo uma celulite tóxica por Wilhelm Frederick Von Ludwig, a Angina de Ludwig pode ser uma celulite extremamente fatal se não houver um diagnóstico preciso e precoce. Tendo vários fatores causal sendo o principal às infecções odontológicas dentre outras como: traumatismos e lacerações dos tecidos bucais, infecções das glândulas salivares, picada de insetos no queixo, neoplasias bucais infectadas, linfadenites, osteonecrose da mandíbula relacionada com o uso de bisfosfonatos. Afetando os espaços fasciais do pescoço, espaço submandibular, espaço submentoniano assim tendo o comprometimento principal as vias aéreas, pacientes imunossuprimidos e com comprometimento na condição sistêmica tendem a ser mais suscetível a Angina de Ludwig. Tendo tratamento a internação imediata e em seguida a prescrição de antibióticos para o controle da infecção e a drenagem cirúrgica para a remoção do material purulento e em seguida a remoção da causa da infecção como extrações e tratamento endodôntico, devido ao comprometimento das vias aéreas em alguns casos mais graves deve se realizar uma traqueostomia ou intubação endotraqueal. Este trabalho visa o melhor entendimento sobre o manejo de pacientes com Angina de Ludwig oferecendo ao leitor um conhecimento sobre a etiologia, diagnóstico e tratamento, bem como o prognostico relativo ao tratamento estabelecido.

Palavras-chave: Angina de Ludwig. Obstrução das vias respiratórias. Infecção focal.

\section{ABSTRACT}

Described in 1836 as being a toxic cellulite by Wilhelm Frederick von Ludwig, Ludwig's Angina can be an extremely deadly cellulite if there is no precise and early diagnosis. There are several causal factors, including dental infections and lacerations of the oral tissues, infections of the salivary glands, insect bites on the chin, infected oral cancers, lymphadenitis, and osteonecrosis of the mandible related to the use of bisphosphonates. Affecting the fascial spaces of the neck, submandibular space, submental space thus having the main involvement of the airways, immunosuppressed patients and compromised systemic condition tend to be more susceptible to Ludwig's Angina. Having immediate hospitalization treatment and then the prescription of antibiotics for infection control and surgical drainage to remove the purulent material and then the removal of the cause of the infection as extractions and endodontic treatment due to the involvement of the airways in some severe cases a tracheostomy or endotracheal intubation should performed. This work aims at a better understanding of the management of patients with Ludwig's Angina, offering the reader a knowledge about the etiology, diagnosis and treatment, as well as the prognosis related to the established treatment.

Keywords: Ludwig's Angina. Airway obstruction. Focal Infection. 


\section{INTRODUÇÃO}

Angina de Ludwig foi descrita pela primeira vez por Wilhem Friedrich Von Ludwig em 1836 como uma celulite tóxica1. Essa celulite comumente é fatal sendo uma necrose progressiva que promove edema nos tecidos moles, elevando e deslocando posteriormente a língua ${ }^{2}$. Essa infecção decorre de variadas origens, sendo frequentemente originárias de infecções odontogênicas ${ }^{1,3} \mathrm{e}$ envolve os espaços fasciais submandibulares, sublinguais e submentonianos ${ }^{1}$.

Apesar da maioria dos casos de Angina de Ludwig ser relacionados a infecções odontogênicas, outros fatores causais como: traumatismos e lacerações dos tecidos bucais, infecções das glândulas salivares, picada de insetos no queixo, neoplasias bucais infectadas, linfadenites, osteonecrose da mandíbula relacionada com o uso de bisfosfonatos $^{4-7}$, podem levar o paciente a este estado patológico.

A compreensão da anatomia dos espaços fasciais é imprescindível para o diagnóstico e tratamento de infecção, uma vez que a fáscia é uma barreira eficaz à difusão da infecção. As infecções odontogênicas, ocasionalmente, se espalham para além dos espaços fasciais do pescoço, sendo que o espaço submandibular é um dos primeiros a ser envolvido por infecção. Essa infecção se dá por dois espaços potenciais que se estendem a partir do assoalho bucal para baixo para a camada superficial da fáscia cervical profunda, uma vez que envolve o espaço entre a mandíbula e o osso hióide. O músculo milohióideo atravessa o espaço horizontal e divide-o em um compartimento supra milohióideo, também conhecido como o espaço sublingual, e um compartimento infra milohióideo, também conhecido como espaço submandibular. Esses dois espaços se comunicam livremente ao longo da face posterior do músculo milohióideo, sendo que as infecções geralmente se espalham para o espaço para-faríngeo posteriormente e para o espaço visceral anterior inferiormente ${ }^{8}$.

Essa celulite é potencialmente fatal, uma vez que dentre as suas complicações estão a obstrução das vias aéreas, trombose na veia jugular interna, mediastinite, pericardite, empiema pleural, desconforto respiratório, trombose do seio cavernoso, sepse, desconforto respiratório, intravascular disseminada coagulação, pleuropulmonar supuração e hematogênica disseminação para órgãos distantes ${ }^{2,5,8}$. Algumas condições sistêmicas podem contribuir para a evolução do quadro infeccioso, dentre eles o HIV, o alcoolismo, diabetes Mellitus, desnutrição, anemia, pacientes imunodeprimidos ou que fazem uso de anti-inflamatórios hormonais ou imunossupressores ${ }^{9-10}$.

O diagnóstico correto e precoce pode proporcionar uma abordagem precisa e eficaz para o tratamento da Angina de Ludwig e das complicações relativa à doença. Sendo assim torna-se importante esclarecer os profissionais sobre os diferentes aspectos relativos a essa infecção. Portanto, o objetivo desse estudo foi revisar a literatura a fim de proporcionar ao cirurgião dentista conhecimento para que possa realizar um diagnóstico eficiente e o encaminhamento do tratamento.

\section{REVISÃO DE LITERATURA}

A Angina de Ludwig é uma celulite frequentemente originada de uma infecção odontogênica classicamente localizada no segundo e terceiro molares inferiores, que envolve os espaços submandibular, sublingual e submentoniano ${ }^{11-12}$.

\begin{tabular}{|c|c|c|c|c|}
\hline Autoria (ano) & $\begin{array}{c}\text { Número } \\
\text { de } \\
\text { pacientes }\end{array}$ & Causas & Condição & Associações sistêmicas \\
\hline $\begin{array}{l}\text { Zanini et al. } \\
(2003)^{11}\end{array}$ & 1 & Odontogênica/gestação & $\begin{array}{l}\text { Dentes em mal estado } \\
\text { de conservação com o } \\
\text { segundo molar inferior } \\
\text { severamente afetado }\end{array}$ & Gestação \\
\hline $\begin{array}{l}\text { Soares et al. } \\
(2004)^{12}\end{array}$ & 1 & Odontogênica & $\begin{array}{l}\text { Exodontia do terceiro } \\
\text { molar não- } \\
\text { erupcionado }\end{array}$ & \\
\hline $\begin{array}{l}\text { Fogaça et } \\
\text { al.(2004) }\end{array}$ & 1 & Odontogênica & $\begin{array}{l}\text { Exodontia do segundo } \\
\text { molar }\end{array}$ & \\
\hline $\begin{array}{l}\text { Gulinelli et al. } \\
(2007)^{14}\end{array}$ & 2 & $\begin{array}{l}\text { Vícios/pneumonia } \\
\text { crônica/sorologia } \\
\text { positiva }\end{array}$ & $\begin{array}{l}\text { Tabaco, etilista } \\
\text { crônico, periodontite } \\
\text { avançada. Exodontia } \\
\text { do primeiro molar }\end{array}$ & $\begin{array}{l}\text { Pneumonia crônica e soro } \\
\text { positivo para HIV }\end{array}$ \\
\hline $\begin{array}{l}\text { Tavares et al. } \\
(2009)^{10}\end{array}$ & 1 & Odontogênica & $\begin{array}{l}\text { Dor de origem } \\
\text { dentária }\end{array}$ & \\
\hline $\begin{array}{l}\text { Kassam; } \\
\text { Messiha; } \\
\text { Heliotis } \\
(2013)^{15}\end{array}$ & 1 & Odontogênica & $\begin{array}{l}\text { Dor de origem } \\
\text { dentária }\end{array}$ & \\
\hline $\begin{array}{l}\text { Banu; } \\
\text { Srikanth } \\
(2014)^{16} \\
\end{array}$ & 1 & Odontogênica & Cárie no elemento 38 & Pós-parto \\
\hline $\begin{array}{l}\text { Campos et al. } \\
(2014)^{17}\end{array}$ & 1 & Odontogênica & $\begin{array}{l}\text { Molares inferiores do } \\
\text { lado esquerdo }\end{array}$ & Dengue \\
\hline $\begin{array}{l}\text { Durazzo et al. } \\
(1997)^{18}\end{array}$ & $\begin{array}{l}1 \\
1 \\
1 \\
1\end{array}$ & $\begin{array}{l}\text { Odontogênica } \\
\text { Odontogênica } \\
\text { Odontogênica } \\
\text { Odontogênica }\end{array}$ & $\begin{array}{l}\text { Segundo mola inferior } \\
\text { direito } \\
\text { Segundo pré- molar } \\
\text { inferior esquerdo }\end{array}$ & Diabetes melitotipol \\
\hline $\begin{array}{l}\text { Brommelstro } \\
\text { et al. }(2001)^{19} \\
\text { Suehara et al. } \\
(2011)^{20}\end{array}$ & $\begin{array}{l}1 \\
1 \\
25\end{array}$ & $\begin{array}{l}\text { Odontogênica } \\
\text { Odontogênica } \\
\text { Odontogênica/tabaco }\end{array}$ & $\begin{array}{l}\text { Odontalgia molar } \\
\text { inferior esquerdo } \\
\text { Odontalgia inferior } \\
\text { direita } \\
\text { Tonsila }\end{array}$ & Diabetes mellitus \\
\hline $\begin{array}{l}\text { Candamourty } \\
\text { et al. (2012) }\end{array}$ & 1 & Odontogênica & Segundo molar & \\
\hline $\begin{array}{l}\text { Tucunduva et } \\
\text { al. }(2013)^{21}\end{array}$ & 1 & Odontogênica & & \\
\hline $\begin{array}{l}\text { Abuabara et } \\
\text { al. }(2012)^{22}\end{array}$ & 1 & Odontogênica & Segundo molar & \\
\hline
\end{tabular}




\begin{tabular}{|l|c|l|l|l|}
\hline $\begin{array}{l}\text { Fellini et al. } \\
(\mathbf{2 0 1 5})^{23}\end{array}$ & 1 & Odontogênica & Usuária de cocaina & \\
\hline $\begin{array}{l}\text { Saifeldeen; } \\
\text { Evans } \\
(\mathbf{2 0 0 4})^{24}\end{array}$ & 1 & Odontogênica & Extração dentária & \\
\hline $\begin{array}{l}\text { Larawin et al. } \\
(\mathbf{2 0 0 6})^{25}\end{array}$ & 103 & Odontogênica & & $\begin{array}{l}\text { Sindrome da } \\
\text { imunodeficiência } \\
\text { adquirida, tuberculose, } \\
\text { linfadenite, Diabetes } \\
\text { Mellitos e desnutrição }\end{array}$ \\
\hline $\begin{array}{l}\text { Freire et al. } \\
(\mathbf{2 0 1 4})^{28}\end{array}$ & 1 & Odontogênica & $\begin{array}{l}\text { Pericoronarite/raiz } \\
\text { residual dente 46, } \\
\text { cárie 47 e 43 }\end{array}$ & \\
\hline $\begin{array}{l}\text { Osunde et al. } \\
(\mathbf{2 0 1 4})^{27}\end{array}$ & 10 & $\begin{array}{l}\text { Odontogênica/desconhe } \\
\text { cida }\end{array}$ & & Gestação \\
\hline
\end{tabular}

Figura 1 - Etiologia e associações sistêmicas das infecções.

A predisposição a Angina de Ludwig por acometimento sistêmico pode advir de doenças como a síndrome da imunodeficiência adquirida, alcoolismo, glomerulonefrites, desnutrição, diabetes mellitus, uso de drogas anti-inflamatórias hormonais ou imunossupressoras bem como anemia aplástica. Outras causas são encontradas, tais como as osteomielites, infecções de glândulas salivares, neoplasias orais infectadas, abscessos peri-amigdalianos, otite média, piercing na língua e o uso de drogas injetáveis nos grandes vasos cervicais ${ }^{28}$.

As doenças sistêmicas e dependentes químicos devem ser motivo de preocupação, uma vez que são mais susceptíveis as complicações durante o tratamento da Angina de Ludwig. As associações sistêmicas mais frequentes são Diabetes Melitus, anemia e hipertensão, e o vício mais comum é o cigarro ${ }^{6}$.

\begin{tabular}{|c|c|c|c|}
\hline Autoria (ano) & Sinais clinicos & Exames de imagem & Antibiograma \\
\hline $\begin{array}{l}\text { Zanini et al. } \\
(2003)^{11}\end{array}$ & $\begin{array}{l}\text { Dentes em mal estado } \\
\text { Tumoração submandibular esq. } \\
\text { Edema de assoalho de boca, } \\
\text { trismo, e sinais de insuficiênncia } \\
\text { respiratória }\end{array}$ & Celulite extensa e sinais de gás & $\begin{array}{l}\text { Gram-positivos e bacilos } \\
\text { Gram-negativos, sugestiva de } \\
\text { flora anaeróbia }\end{array}$ \\
\hline $\begin{array}{l}\text { Soares et al. } \\
(2014)^{12}\end{array}$ & $\begin{array}{l}\text { Aumento de volume de } \\
\text { consistência firme, bilateralmente } \\
\text { nas regiōes submandibulares e } \\
\text { sublinguais, hiperemia }\end{array}$ & $\begin{array}{l}\text { Coleção de aspecto inflamatório, } \\
\text { apresentando conteúdo liquida e } \\
\text { gasoso em seu interior }\end{array}$ & Streptococcus b-hemolitico \\
\hline $\begin{array}{l}\text { Fogaça et al. } \\
(2006)^{3}\end{array}$ & $\begin{array}{l}\text { Dispneico, disfágico, disfónico, } \\
\text { febril, toxémico }\end{array}$ & $\begin{array}{l}\text { Coleção purulenta nos espaços } \\
\text { fasciais e desvio da traqueia }\end{array}$ & Leucocitose de $19.900 / \mathrm{mm}^{2}$ \\
\hline $\begin{array}{l}\text { Gulinelli et al. } \\
(2007)^{14}\end{array}$ & $\begin{array}{l}\text { Febril, séptico, aumento } \\
\text { volumétrico submandibular e } \\
\text { submentoniano, abaulamento do } \\
\text { assoalho bucal, hiperemia em } \\
\text { regiảo cervical }\end{array}$ & $\begin{array}{l}\text { Imagem radiolúcida indicativa de } \\
\text { fratura de corpo posterior } \\
\text { mandibular esquerdo, com o } \\
\text { dente } 48 \text { na linha de fratura }\end{array}$ & $\begin{array}{l}\text { Leucocitose com acentuado } \\
\text { desvio a esquerda } \\
\text { Pseudomonas e } \\
\text { Straptococcusyiridans }\end{array}$ \\
\hline $\begin{array}{l}\text { Tavares et al. } \\
(2008)^{10} \\
\text { Kassam; } \\
\text { Messiha; } \\
\text { Heliotis (2013) }\end{array}$ & $\begin{array}{l}\text { Aumento de volume na regiāo } \\
\text { submentoniana e submandibular } \\
\text { bilateral, apresentando zonas de } \\
\text { flutuaçăo e tórax avermelhado e } \\
\text { edemaciado } \\
\text { Dificuldade progressiva da } \\
\text { deglutiçăo, odinofagia, disfonia, } \\
\text { trismo, inchaço extra-oral, e dor }\end{array}$ & $\begin{array}{l}\text { Secreção no espaço } \\
\text { subcutâneo, no retrofaringeo e } \\
\text { no mediastino superior }\end{array}$ & $\begin{array}{l}\text { Leucócitos de } 18100 / \mathrm{mm}^{3} \text {, } \\
\text { com neutrófilia e desvio a } \\
\text { esquerda }\end{array}$ \\
\hline $\begin{array}{l}\text { Banu, Srikanth } \\
(2014)^{16}\end{array}$ & $\begin{array}{l}\text { Febre e mal-estar acompanhada } \\
\text { por dor e inchaço em sua região } \\
\text { submandibular esquerda, que } \\
\text { rapidamente avançou para a sub- } \\
\text { região mental e para a direita } \\
\text { região submandibular }\end{array}$ & & Neutrófilos 16.000 células \\
\hline
\end{tabular}

\begin{tabular}{|c|c|c|c|}
\hline $\begin{array}{l}\text { Campos et al. } \\
(2014)^{17}\end{array}$ & $\begin{array}{l}\text { Inchaço em região } \\
\text { submandibular, protrusāo da } \\
\text { lingua, além de edema da glote, } \\
\text { estridor laringeo, e trismo }\end{array}$ & $\begin{array}{l}\text { Abaulamento dos recidos moles } \\
\text { hemifaceesquerdamovendo-se } \\
\text { fora do músculo masseter; } \\
\text { inchaço dos tecidos moles na } \\
\text { regiăo cervical anterior bilateral, } \\
\text { com áreas hipodensas e direito } \\
\text { contraste impregnação e inferior } \\
\text { ao submandibular glândula }\end{array}$ & \\
\hline \multirow[t]{2}{*}{$\begin{array}{l}\text { Durazzo et al. } \\
(1997)^{18}\end{array}$} & $\begin{array}{l}\text { Abaulamento e dor na região } \\
\text { submandibular há } 6 \text { meses } \\
\text { Abaulamento em região cervical } \\
\text { lateral há } 1 \text { semana, febre e } \\
\text { intensa dor }\end{array}$ & $\begin{array}{l}\text { Abcesso na loja submandibular } \\
\text { esquerda com aumento de parte } \\
\text { mole e formação de gás } \\
\text { Abscesso na região cervical } \\
\text { lateral esquerda com formação }\end{array}$ & $\begin{array}{l}\text { Esherichia coli } \\
21.000 \text { leucócitos } \\
\text { Staphylococcus aureus }\end{array}$ \\
\hline & $\begin{array}{l}\text { Dor, tumor, febre e disfagia } \\
\text { Dor, febre e tumor masseterino e } \\
\text { submandibular }\end{array}$ & $\begin{array}{l}\text { de gás e dissecção de vários } \\
\text { planos do pescoço. O feixe } \\
\text { vásculo-nervoso estava } \\
\text { localizado medialmente ao } \\
\text { abscesso } \\
\text { Extensa coleçåo retrofaringea } \\
\text { retroestemal, mediastinica, } \\
\text { derrame pleural, } \\
\text { roncopneumonia extenso, } \\
\text { abscesso parafaríngeo }\end{array}$ & \\
\hline $\begin{array}{l}\text { Brommelstro et } \\
\text { al. }(2001)^{19}\end{array}$ & $\begin{array}{l}\text { Odinofagia, aumento de volume } \\
\text { da região submandibular, dor } \\
\text { torácica anterior ventilatório- } \\
\text { dependente abaulamento do } \\
\text { palato mole e trismo } \\
\text { Aumento de volume local, } \\
\text { odinofagia, trismo, disfagia e } \\
\text { febre }\end{array}$ & $\begin{array}{l}\text { Coleção residual } \\
\text { Aumento de volume na região } \\
\text { cervical, presença de coleção } \\
\text { hipodensa na região } \\
\text { submandibular e supraclavicular }\end{array}$ & $\begin{array}{l}\text { Leucocitose com desvio } \\
\text { acentuado a esquerda } \\
\text { Streptococcusviridans e } \\
\text { Peptostresptococcus } \\
\text { Leucocitose com desvio a } \\
\text { esquerda } \\
\text { Streptococcusviridans e } \\
\text { Bacteroides fragilis }\end{array}$ \\
\hline $\begin{array}{l}\text { Suehara et al. } \\
(2011)^{20}\end{array}$ & Aumento de volume, dor, febre & & Staphylococcus aureus \\
\hline $\begin{array}{l}\text { Candamourty et } \\
\text { al. }(2012)^{2}\end{array}$ & $\begin{array}{l}\text { Incapacidade para abrir a } \\
\text { boca, dor e inchaço em relação a } \\
\text { mandibula }\end{array}$ & & \\
\hline $\begin{array}{l}\text { Tucunduva et } \\
\text { al. }(2013)^{21}\end{array}$ & Febre, edema e dor local & $\begin{array}{l}\text { Infiltrado inflamatório com } \\
\text { liquido e gás }\end{array}$ & \\
\hline $\begin{array}{l}\text { Abuabara et al. } \\
(2012)^{22}\end{array}$ & $\begin{array}{l}\text { Fistula, inchaço na região de } \\
\text { sulco lábial }\end{array}$ & $\begin{array}{l}\text { Restauração oclusal e rarefação } \\
\text { óssea ao redor do ápice do } \\
\text { segundo molar consistênte com } \\
\text { abcesso apical crônico }\end{array}$ & \\
\hline $\begin{array}{l}\text { Fellini et al. } \\
(2015)^{23}\end{array}$ & $\begin{array}{l}\text { Dispneia, dor região mandibular e } \\
\text { cervical, hiperemia, } \\
\text { enfisema, odonofagia }\end{array}$ & $\begin{array}{l}\text { Comprometimento da região } \\
\text { mediastinal, gás que dissecava } \\
\text { os planos musculares e } \\
\text { adiposos }\end{array}$ & \\
\hline $\begin{array}{l}\text { Saifeldeenk; } \\
\text { Evans }(2004)^{24}\end{array}$ & $\begin{array}{l}\text { Salivação, dispnéia, disfagia, } \\
\text { inchaço e celulite }\end{array}$ & & \\
\hline $\begin{array}{l}\text { Larawin et al. } \\
(2006)^{25}\end{array}$ & $\begin{array}{l}\text { Inchaço, trismo, eritema, disfagia, } \\
\text { dor de dente e estridor }\end{array}$ & $\begin{array}{l}\text { Abcesso retrofaringeo, parótida } \\
\text { e parafaringeo }\end{array}$ & \\
\hline $\begin{array}{l}\text { Freire et al. } \\
(2014)^{26}\end{array}$ & $\begin{array}{l}\text { Aumento de volume, odinofagia, } \\
\text { disfagia e queixa álgica intensa }\end{array}$ & & $\begin{array}{l}\text { Leucócito } 19.2 / \text { hematócrito } \\
29.1 \% \text { hemoglobina } 10.5 \mathrm{~g} / \mathrm{dl}\end{array}$ \\
\hline
\end{tabular}

Figura 2 - Diagnóstico.

O diagnóstico precoce é importante para que o profissional consiga ter a atenção aos sintomas específicos sugestivos de comprometimento das vias aéreas, devido alguns sintomas representarem emergência e podendo rapidamente progredir para uma ameaça a vida do paciente devido a perda da via aérea ${ }^{29}$.

Ela possui como sintomatologia dor torácica angústia respiratória e dispnéia e em seu exame clinico pode ser observado enrijecimento do assoalho bucal, dificuldades na deglutição, elevação da língua e obstruções das vias aéreas nos casos considerados graves. Devido aos riscos dos pacientes com essa enfermidade o diagnóstico precoce é considerado o meio mais seguro para esses pacientes ${ }^{10}$. 


\begin{tabular}{|c|c|c|c|c|}
\hline Autoria (ano) & Prescrição inicial & $\begin{array}{l}\text { Prescrição pós- } \\
\text { antibiograma }\end{array}$ & Tratamento local & $\begin{array}{c}\text { Taxa de } \\
\text { mortalidade }\end{array}$ \\
\hline $\begin{array}{l}\text { Zanini et al. } \\
(2003)^{11}\end{array}$ & $\begin{array}{l}\text { Clindamicina }(600 \mathrm{mg} \\
\text { intravenoso de } 8) \mathrm{em} 8 \\
\text { horas ecefrtiaxone }(1 \mathrm{~g} \\
\text { intravenoso de } 12 \mathrm{em} \\
12 \text { horas) }\end{array}$ & $\begin{array}{l}\text { Clindamicina (gram- } \\
\text { positivos e anaeróbios) } \\
\text { Ceftriaxone (gram- } \\
\text { negativos) }\end{array}$ & $\begin{array}{l}\text { Antibioticoterapia e } \\
\text { drenagem cirúrgica }\end{array}$ & \\
\hline $\begin{array}{l}\text { Soares et al. } \\
(2014)^{12}\end{array}$ & $\begin{array}{l}\text { Clindamicina (600mg } \\
\text { EV, de } 8 \text { em } 8 \text { horas), } \\
\text { Gentamicina ( } 140 \mathrm{mg} \\
\text { EV) }\end{array}$ & Amoxicilina & $\begin{array}{l}\text { Antibioticoterapia, drenagem } \\
\text { intra bucal }\end{array}$ & \\
\hline $\begin{array}{l}\text { Fogaça et al. } \\
(2006)^{13}\end{array}$ & & $\begin{array}{l}\text { Penicilina G cristalina } \\
4.000 .000 \text { de } 4 / 4 \text { horas, } \\
\text { Amicacina } 500 \mathrm{mg} \text { de } \\
12 / 12 \text { horas e } \\
\text { metronidazol } 500 \mathrm{mg} \text { de } \\
8 / 8 \text { horas }\end{array}$ & $\begin{array}{l}\text { Traqueotomia, acessos } \\
\text { submandibular direito e } \\
\text { submental com drenos de } \\
\text { Penrose intercomunicantes } \\
\text { e cervicotomia }\end{array}$ & \\
\hline $\begin{array}{l}\text { Gulinelli et } \\
\text { al.(2007) }\end{array}$ & & & & \\
\hline $\begin{array}{l}\text { Tavares et al. } \\
(2008)^{10}\end{array}$ & & $\begin{array}{l}\text { Cefalotina } 1 \mathrm{~g} \text { de } 6 / 6 \\
\text { horas EV, Gentamicina } \\
240 \mathrm{mg}+\text { água destilada } \\
\text { em dose única diária EV e } \\
\text { Metronidazol } 500 \mathrm{mg}+ \\
\text { água destilada de } 8 / 8 \\
\text { horas EV }\end{array}$ & $\begin{array}{l}\text { Drenagem cirúrgica através } \\
\text { de múltiplas incisōes, } \\
\text { finalizando com instalaçăo } \\
\text { de drenos de Pen rose }\end{array}$ & \\
\hline $\begin{array}{l}\text { Kassam; } \\
\text { Messiha; } \\
\text { Heliotis } \\
(2013)^{15} \\
\end{array}$ & $\begin{array}{l}\text { Dexametasona e } \\
\text { adrenalina }\end{array}$ & & $\begin{array}{l}\text { Intubaçăo, extração dos } \\
\text { terceiros molares } \\
\text { bilateralmente com } \\
\text { descompressão e drenos }\end{array}$ & \\
\hline $\begin{array}{l}\text { Banu; Srikanth } \\
(2014)^{16}\end{array}$ & & $\begin{array}{l}\text { Ampicilina consistindo de } \\
1 \mathrm{~g} \text {, clindamicina } \\
600 \mathrm{mg} \text {, gentamicina } 80 \\
\mathrm{mg} .\end{array}$ & $\begin{array}{l}\text { Drenagem cirúrgica com } \\
\text { incisão profunda em espaço } \\
\text { sublingual, drenagem do } \\
\text { lado esquerdo e extração do } \\
\text { elemento } 38\end{array}$ & \\
\hline $\begin{array}{l}\text { Campos et al. } \\
(2014)^{16}\end{array}$ & $\begin{array}{l}\text { Piperacilina, } \\
\text { Tazobactam } \\
\text { intravenosa, } \\
\text { hidrocortisona, e } \\
\text { plaquetas transfusōes. } \\
\end{array}$ & & $\begin{array}{l}\text { Intubação orotraqueal, o } \\
\text { paciente foi submetido a } \\
\text { uma traqueotomia de } \\
\text { emergência e secreção } \\
\text { purulenta }\end{array}$ & \\
\hline $\begin{array}{l}\text { Kataria et al. } \\
(2015)^{5}\end{array}$ & $\begin{array}{l}\text { Amoxicilina, clavulanato } \\
\text { e metronidazol }\end{array}$ & & & 1 \\
\hline $\begin{array}{l}\text { Durazzo et al. } \\
(1997)^{18}\end{array}$ & $\begin{array}{l}\text { Antibiótico e anti- } \\
\text { inflamatório năo- } \\
\text { hormonal, Penicilina } \\
\text { Cristalina, Amicacina e } \\
\text { Fenoximetilpenicilina }\end{array}$ & $\begin{array}{l}\text { Clindamicina } \\
\text { Cefalotina e Metronidazol }\end{array}$ & $\begin{array}{l}\text { Tratamento 11L11úrgico } \\
\text { Drenagem do abcesso feito } \\
\text { por cervicotomia lateral } \\
\text { esquerda e drenos de } \\
\text { penrose } \\
\text { Antibiótico, } \\
\text { drenagem, toracotomia e } \\
\text { traqueostomia }\end{array}$ & \\
\hline $\begin{array}{l}\text { Brommelstr et } \\
\text { al. }(2001)^{19}\end{array}$ & & & $\begin{array}{l}\text { Toracotomia pósterolateral } \\
\text { direita, com ampla abertura } \\
\text { da pleura mediastinal. } \\
\text { Drenagem cirúrgica, } \\
\text { toracotomia póstero-lateral } \\
\text { direita com ampla abertura } \\
\text { da pleura mediastinal } \\
\end{array}$ & \\
\hline $\begin{array}{l}\text { Sueharal et al. } \\
(12011)^{20}\end{array}$ & Vancomicina/Penicilina & & Cervicotomia e toracotomia & 10 \\
\hline $\begin{array}{l}\text { Candamourt el } \\
\text { al. }(2012)^{2}\end{array}$ & & $\begin{array}{l}\text { A administração } \\
\text { intravenosa de cefotaxima } \\
1 \mathrm{~g} \text {, Gentamicina } 80 \mathrm{mg} \text {, } \\
\text { metrogyl } 500 \mathrm{mg}\end{array}$ & $\begin{array}{l}\text { Drenagem e estração do } \\
\text { dente }\end{array}$ & \\
\hline $\begin{array}{l}\text { Tucunduva et } \\
\text { al. }(2013)^{21}\end{array}$ & & & Drenagem & \\
\hline $\begin{array}{l}\text { Abuabara et } \\
\text { al. (2012) }\end{array}$ & $\begin{array}{l}\text { Antibioticoterapia } \\
\text { (Cefalosporina) }\end{array}$ & $\begin{array}{l}\text { Cloridrato de } \\
\text { Clindamicina } 300 \mathrm{mg} \text { a } \\
\text { cada } 8 \text { horas }\end{array}$ & Drenagem & \\
\hline $\begin{array}{l}\text { Fellini et al. } \\
(2015)^{23}\end{array}$ & & & $\begin{array}{l}\text { Sedaçăo com midazolam } \\
\text { associado ao fentanil e } \\
\text { procedimento cirúrgico }\end{array}$ & \\
\hline \begin{tabular}{l|} 
Saifeldeenk; \\
Evans $(2004)^{24}$
\end{tabular} & Antibiótico & $\begin{array}{l}6 \mathrm{mg} \\
\text { Dexametasonaintravenos } \\
\text { a, } 1,2 \mathrm{~g} \text { de Augmentin, } \\
\text { hidratação venosa, } \\
\text { nebulização e adrenalina }\end{array}$ & Traqueostomia e drenagem & \\
\hline
\end{tabular}

\begin{tabular}{|c|c|c|c|c|}
\hline $\begin{array}{l}\text { Larawin et al. } \\
\left(\mathbf{2 0 0 6 ) ^ { 2 5 }}\right.\end{array}$ & & $\begin{array}{l}\text { cloranfenicol, } \\
\text { metronidazol, } \\
\text { flucloxacilina, gentamicina } \\
\text { e ceftazidima }\end{array}$ & $\begin{array}{l}\text { Incisão, drenagem, } \\
\text { traqueostomia }\end{array}$ & 4 \\
\hline $\begin{array}{l}\text { Freire et al. } \\
(2014)^{26}\end{array}$ & $\begin{array}{l}\text { Penicilina G cristalina } \\
5.000 .000 \text { IV } 4 / 4 \text { horas, } \\
\text { associada à } \\
\text { metronidazol } 500 \mathrm{mg} \text { IV } \\
8 / 8 \text { horas; analgesia } \\
\text { realizada com tramadol } \\
100 \mathrm{mg} \text { IV } 12 / 12 \text { horas e } \\
\text { dipirona sódica } 1 \mathrm{~g} \text { IV } \\
6 / 6 \text { horas }\end{array}$ & $\begin{array}{l}\text { Gentamicina } 240 \mathrm{mg} \text { EV } \\
24 / 24 \mathrm{~h} \text { e Clindamicina } \\
600 \mathrm{mg} \text { EV 08/08 horas }\end{array}$ & $\begin{array}{l}\text { Desbridamento cirúrgico, } \\
\text { remoçăo do } 46,47 \text { e } 48\end{array}$ & \\
\hline
\end{tabular}

Figura 3 - Tratamento.

A prescrição antibiótica é uma condição fundamental para o controle desta infecção e evitar o agravamento do quadro clínico do paciente ${ }^{29-32}$. O uso intravenoso de antibióticos em altas doses é essencial no tratamento desses pacientes sendo que inicialmente institui-se uma antibioticoterapia empírica ${ }^{13,30-31,33-34}$ até que se obtenha o resultado do exame bacteriológico cultural e o antibiograma para melhor direcionar a terapêutica ${ }^{13,30-31,34}$.

O primeiro passo é a internação imediata do paciente com infecção na região de pescoço para a manutenção das vias aéreas, administração de antibióticos intravenosa e soro. $\mathrm{Na}$ ausência de uma adequada via de respiração rapidamente deve-se realizar uma traqueostomia ou intubação endotraqueal $\mathrm{l}^{30-31,34}$.

O manejo inadequado pode romper o abscesso resultando na aspiração de material purulento com complicações pulmonares subsequentes. Se houver presença de edema, manipulação excessiva da via aérea não é aconselhada, pois pode causar sangramento ou laringoespasmo que necessitem de uma via aérea cirúrgica emergente. Em muitos pacientes, a intubação oral não é possível. Por isso recomenda-se a gestão das vias respiratórias com uma intubação por meio de fibra óptica ou uma traqueotomia ${ }^{29}$.

Há riscos e benefícios associados à traqueotomia, e cada caso deve ser considerado individualmente. A escolha do procedimento deve basear-se em questões, incluindo o plano cirúrgico, comprimento da intubação, estado do paciente, devido ao inchaço do pescoço poder obscurecer os marcos cirúrgicos usuais e causar desvio da traqueia ${ }^{32}$.

Quando a infecção apresenta ponto de flutuação, a intervenção cirúrgica é indicada, para debridamento e drenagem dos espaços infeccionados. A base para a terapia é a remoção da causa. Independente se for através do tratamento endodôntico, curetagem gengival, ou exodontia. Intervenção cirúrgica sob a forma de drenagem cirúrgica é obrigatório, com os seguintes princípios recomendados: incisões em pele e mucosa quando possível, não no local de flutuação máxima, porque essas feridas tendem a curar com uma cicatriz desagradável; coloque a incisão em uma dobra natural da pele; sendo a incisão intra ou extra oral, divulcionar o tecido, coloque um dreno para a retirada de toda a secreção e remova os drenos quando não 
houver mais a presença de secreção ${ }^{32}$.

Para prevenir essa patologia, ou de quadros que possam levar a ela é necessário que o cirurgião dentista observe o paciente, após a realização de procedimentos na região posterior da mandíbula, fazendo controles pós-operatórios rigorosos, além de orientar o paciente com relação aos cuidados pós cirúrgicos, uma vez que influenciarão diretamente na recuperação do paciente.

Diagnosticar precocemente a Angina de Ludwig é de extrema importância devido à enorme gama de complicações, várias delas potencialmente fatais ${ }^{28}$. Para esse diagnóstico deve-se considerar que o quadro clínico consiste em hiperemia e edema endurecido da região submandibular, sem ponto de flutuação, tumefação crescente do soalho da boca, que empurra a língua pare cima e para trás, e trismo progressivo. A evolução do caso irá levar o paciente à dificuldade de deglutição, disfonia, com sinais de rouquidão "voz de pato", e dispnéia. Além disso, o paciente pode apresentar febril e com calafrios ${ }^{35-36}$.

Há muito tempo na era pré-antibiótico essa patologia era sinônimo de fatalidade, sendo que na maioria dos casos o paciente viria a óbito, entretanto atualmente o óbito é minoria e os pacientes quase sempre sobrevivem ${ }^{28}$.

\section{CONCLUSÃO}

A Angina de Ludwig não é comum, entretanto é uma condição potencialmente fatal, devido ao risco de obstrução das vias aéreas iminente e a disseminação da infecção, sendo um tratamento de caráter emergencial. $\mathrm{O}$ tratamento deverá ser realizado sempre em âmbito hospitalar e eficaz, baseando se no reconhecimento inicial do processo clínico com o uso adequado de antibióticos parenterais, técnicas de proteção das vias aéreas, e drenagem cirúrgica da infecção, executando um tratamento rápido.

\section{REFERÊNCIAS}

1. Scully C, Langdon J, Evans J. Marathon of eponyms: 12 Ludwig angina. Oral Dis. 2010;16:496-7.

2. Candamourty R, Venkatachalam S, Babu MR, Kumar GS. Ludwig's Angina - an emergency: A case report with literature review. J Nat Sci Biol Med. 2012;3(2):206-8.

3. Kavarodi AM. Necrotizing fasciitis in association with Ludwig's angina - a case report. Saudi Dent J. 2011;23:157-60.

4. Botha A, Jacobs F, Postma, C. Retrospective analysis of etiology and comorbid diseases associated with Ludwig's Angina. Ann Maxillofac Surg. 2015;5(2):168-73.

5. Kataria G, Saxena A, Bhagat S, Singh B, Kaur M, Kaur G. Deep neck space infections: a study of 76 cases. Iran J Otorhinolaryngol. 2015;27(81):293-9.
6. Sakarya EU, Kulduk E, Gündogan O, Soy FK, Dündar R, Kilavuz $\mathrm{AE}$, et al. Clinical features of deep neck infection: analysis of 77 patients. Kulak Burun BogazIhtis Derg. 2015;25(2):102-8.

7. Yang RH, Shen SH, Li WY, Chu YK. Bisphosphonate-related osteonecrosis of the jaw complicated by Ludwig's angina. J Chin Med Assoc. 2015;78(1):76-9.

8. Vieira F, Allen SM, Stocks RM.; Thompson JW. Deep neck infection. Otolaryngology Clin North Am. 2008;41(3):459-83.

9. Fomete B, Agbara R, Osunde DO, Ononiwu CN. Cervicofacial infection in a Nigerian tertiary health institution: a retrospective analysis of 77 cases. J Korean Assoc Oral Maxillofac. 2015;4:293-8.

10. Tavares SSS, Tavares GR, Cavalcanti MOA, Carreira PFS, Cavalcante JP, Paiva MAF. Angina de Ludwig: revisão de literatura e relato de caso. Rev Cir Traumatol Buco-Maxilo-Fac. 2009;9(3):9-14.

11. Zanini FD, Stefani E, Santos JC, Perito LS, Kruel NF. Angina de Ludwig: relato de caso e revisão do manejo terapêutico. Arq Catarinense Med. 2003;32(4):21-3.

12. Soares LP, Silva TSN, Beltrão RC, Oliveira MG, Beltrão GC. Angina de Ludwig associada à presença de corpo estranho em região sublingual. Rev Faculdade Odontol Passo Fundo. 2004;2(9):23-6.

13. Fogaça PFL, Queiroz EA, Kuramochi MM, Vanti LA, Correa JDH. Angina de Ludwig: uma infecção grave. Rev Port Estomatol Cir Maxilofac. 2006;47(3):157-61.

14. Gulineli JL, Esteves JC, Queiroz TP, Riciere CB, Junior IRG. Angina de Ludwig. Robrac.2007;16(42).

15. Kassam K, Messiha A, Heliotis M. Ludwig's Angina: the original angina. Case Rep Surg. 2013.

16. Banu K, Srikanth G. Ludwig's Angina in post partum patient. J Maxillofac Oral. 2014;13(2):208-10.

17. Campos MA, Prota MLCJ, Gomes CA, Amaral KP, Almeida DC. Ludwig's Angina after severe thrombocytopenic purpura associated with dengue fever. Rev Soc Bras Med Trop. 2014;47(1):116-8.

18. Durazzo MD, Pinto FR, Da Rocha Loures MS, Volpi EM, Nishio S, Brandão LG, et al. Os espaços cervicais profundos e seu interesse nas infecções da região. Rev Assoc Med Bras.1997;43(2):119-26

19. Brommelstroet M, Rosa JFT, Boscardim PCB, Shmidlin CA, Shibata S. Mediastinite descendente necrosante pós-angina de Ludwig. J Pneumol. 2001;27(5):269-71.

20. Suehara AB, Gonçalves MBS, Esteves AR, Bertelli AAT, Gonçalves AJ, Kikuchi W, et al. Infecção cervical complicada com mediastinite descendente necrosante: análise de 25 casos. Rev Bras Cir Cabeça Pescoço. 2011;40(4):186-90.

21. Tucunduva MJAPS, Freitas CF, Ogassawara B, Baladi MG, Neto RRCMT. Estudo imaginológico de um caso de Angina de Ludwig. Rev Odontol Univ. 2013;25(2):164-9.

22. Abuabara A, Shramm CA, Zielak JC, Filho FB. Infecção dentária simulando uma lesão de pele. An Bras Dermatol. 2012;87(4):619-21.

23. Fellini RT, Volquind D, Schnor OH, Angeletti MG, Souza OE. Manejo da via aérea na Angina de Ludwig - um desafio: relato de caso. Rev Bras Anestesiol. 2015

24. Saifeldeen K, Evans R. Ludwig's Angina. Emerg Med J. 2004;21:242-3. 
25. Larawin V, Med M, Naipao J, DubeySP. Head and neck infections. Otolaryngol Head Neck Surg.2006;135:889-93.

26. Freire FFP, Dantas RMX, Macedo TFO, Figueiredo LMG, Spíndola LG, Azevedo RA. Fasceitenecrozante facial causada por infecção odontogênica. Rev Cir Traumatol Buco-Maxilo-Fac. 2014;14(1):43-8.

27. Osunde OD, Bassey GO, Ver-or N. Management of Ludwig's Angina in pregnancy: a review of 10 cases. Ann Med Health Sci Res. 2014;4(3):361-4

28. Hueb MM, Borges LM, Oliveira LR. Angina de Ludwig: tratamento cirúrgico minimamente invasivo guiado por ultrassonografia cervical. Rev Bras Otorrinolaringol. 2004;8(3):279-86.

29. Caccamese JF, Coletti DP. Deep neck infections: clinical considerations in aggressive disease. Oral Maxillofac Surg Clin North Am. 2008;20(3):367-80

30. Martins L, Rocha RCA, Santos KCP, Marcucci M, Costa C, Oliveira JX. Angina de Ludwig-considerações sobre conduta e relato de caso. Rev Inst Cienc Saude. 2009;27(4)

31. Osborn TM, Assael LA, Bell RB. Deep space neck infection: principles of surgical management. Oral Maxillofac Surg Clin North Am. 2008;20(3):353-65.

32. Melo TAF, Rucker T, Carmo MPD, Irala LED, Salles AA. Ludwig's angina: diagnosis and treatment. RSBO. 2013;10(2):172-5.

33. Pourdanesh F, Dehghani N, AzarsinaM, Malekhosein Z. Pattern of odontogenic infections at a tertiary Hospital in Tehran, Iran: a 10-year retrospective study of 310 patients. J Dent. 2013;10(4):319-28.

34. Uluibau IC, Jaunay T, Goss AN. Severe odontogenic infections. Aust Dent J. 2005;50:74-81.

35. Rodrigues J, Coelho LB, Bastos RGS, Chayamiti MCL, Delegido RM, Finamore CMJ. Angina de Ludwig: relato de dois casos. Braz J Otorhinolaryngol. 2001; 67(3):411-4.

36. Shulman NJ, Owens B. Medical complications following sucessful pediatric dental treatment. J Clin Ped Dent. 1996;20: 273-5. 